\title{
Opisthotonos: a newly recognized side effect of midazolam
}

\author{
Deniz Yılmaz, Tansu Sipahi
}

Department of Pediatrics, Dr. Sami Ulus Children's Hospital, Ankara, Turkey

\section{To The Editor:}

A 13-month-old boy was admitted to our hospital for investigation of recurrent respiratory symptoms. He had no history of seizure disorder. His laboratory tests were normal. He was taking ampicillin-sulbactam. In order to explain his symptoms, computed tomography (CT) of the chest was planned and midazolam $0.1 \mathrm{mg} / \mathrm{kg}$ was administered intranasally to sedate the patient before obtaining CT. However, the patient developed an opisthotonic posture soon after midazolam administration. It lasted 10 minutes and subsided spontaneously.

Another boy, 12 months of age with a history of reccurent respiratory symptoms was also hospitalized and CT of the chest was planned. He had neither abnormal laboratory test results nor history of seizure disorder. He was taking ceftriaxone sodium. After intranasal administration of midazolam $0.1 \mathrm{mg} / \mathrm{kg}$ to sedate the patient before CT the patient developed opisthotonos, which lasted approximately 15 minutes and subsided spontaneously.

Midazolam is a water-soluble benzodiazepine with sedative and anesthetic effects (1). Side effects of midazolam are hypotension, hypoxia, apnea, gastrointestinal disturbance, headache, tremor, confusion, ataxia, amnesia, vertigo, muscle flaccidity, blood disorder and jaundice. Respiratory depression and respiratory arrest have also been reported (2-5). However, as far as we know, opisthotonos has never been reported as a side effect of midazolam previously. Watanabe et al. (6) reported a 17-year-old patient developed opisthotonos after flumazenil administration which was given to antagonize midazolam. In that study opisthotonos had occurred soon after flumazenil was given so it was attributed to flumazenil administration.

We could not find any reason to explain opisthotonic postures of the patients. We wish to draw attention to opisthotonos as a possible adverse effect of midazolam. Further studies are needed to understand the mechanisms of these adverse effects.

\section{References}

1. Hanhan UA, Fiallos MR, Orlowski JP. Status epilepticus. Pediatr Clin North Am 2001; 48: 683695.

2. Rey E, Treluyer JM, Pons G. Pharmakokinetic optimisation of benzodiazepine therapy for acute seizures. Clin Pharmacokinet 1999; 36: 409-424.

3. Waller D, Renwick A. Principles of Medical Pharmacology. London: Balliere Tindall, 1994.

4. World Health Organization. Symptom relief in terminal illness. Geneva: WHO, 1998.

5. Galbraith A, Bullock S, Manias E, Richards A, Hunt B. Fundamentals of Pharmacology: A Text for Nurses and Health Professionals. Singapore: Addison Wesley Longman, 1999.

6. Watanabe S, Satumae T, Takeshima R, Taguchi N. Opisthotonos after flumazenil administred to antagonize midazolam previously administered to treat developing local anesthetic toxicity. Anesth Analg 1998; 86: 677-678.

Correspondence: Deniz Y1lmaz, M.D.,

Konutkent-2

A3 Blok No:32

Çayyolu,

Ankara, Turkey.

E-mail: dayilmaz2002@yahoo.com

Received: October 14, 2003.

Revised: November 19, 2003.

Accepted: November 24, 2003 